\title{
A CROSS-SECTIONAL STUDY ON SELF MEDICATION PATTERN AMONG MEDICAL STUDENTS AT KANNUR, NORTH KERALA
}

Girish H.O'1, Divya H.M², Sarada Prabhakaran³, Venugopalan P.P4, Raghavendraswamy Koppad5, Abhishek Acharya ${ }^{6}$

\section{HOW TO CITE THIS ARTICLE:}

Girish HO, Divya HM, Sarada Prabhakaran, Venugopalan PP, Raghavendraswamy Koppad, Abhishek Acharya. "A crosssectional study on self medication pattern among medical students at Kannur, North Kerala". Journal of Evolution of Medical and Dental Sciences 2013; Vol. 2, Issue 45, November 11; Page: 8693-8700.

ABSTRACT: BACKGROUND: Self medication is mainly symptomatic based and may lead to the masking of signs and symptoms of underlying disease. Medical students being exposed to the subjects in medicine are more prone for self medication. This raises the concerns of incorrect selfdiagnosis, drug interaction, and use of drugs other than for the original indication. AIMS: To study the pattern of self medication among medical students and to determine the factors affecting it. METHODS AND MATERIAL: STUDY DESIGN \& SETTING: A cross-sectional descriptive study done in a medical college. Study Duration: March $15^{\text {th }}$ to April 20 th 2013 . Participants: Out of 400 students, 302 students who were willing to participate and available during study period were enrolled in the study. Representation from all phases/batches of MBBS course was ensured, accounting to 77, 84, 63 and 78 students from first, second, third and final phase of MBBS. Data collection: By self administered pre-tested \& validated questionnaire. Statistical analysis was done by applying proportions/percentages. RESULTS: Out of 302 participants, $25.8 \%$ were males \& $74.2 \%$ were females. Practice of self medication was reported by $64.9 \%$ students. It was $16.9 \%$ in first phase students which shoot to $100 \%$ in final phase. Practice of self medication was higher in males while the frequency of self medication was higher in females. Seniors $(89.8 \%)$ and previous prescriptions (87.2\%) were the most common sources for reference. Fever (70.4\%), common cold $(67.8 \%)$ and headache/bodyache $(64.7 \%)$ were the common reasons for self medication. Analgesics (79.6\%), antipyretics (79.6\%) and anti-histaminic (72.4\%) were the most common drugs used for self medication. $30.1 \%$ of them took antibiotics and $9.7 \%$ sedatives without prescription. $80.1 \%$ (157) of those who took self medication said that they prescribed drugs for others also (friends/relatives). None of them suffered any adverse effects. CONCLUSIONS: The practice of self medication is widely prevalent in medical students especially among third and final phase students. This may possibly mask the initial signs and symptoms of diseases and lead to making a wrong diagnosis and risk of using a wrong drug. This highlights the importance of impressing the students about the dangers of self medication, their misuse and their responsibility.

KEY WORDS: Medical students, self medication, drugs.

INTRODUCTION: Self-medication can be defined as the use of drugs to treat self-diagnosed disorders or symptoms, or the intermittent or continued use of a prescribed drug for chronic or recurrent disease or symptoms.(1,2) Since self medication is mainly symptomatic based and taken without evaluation by qualified practitioner, it may lead to the masking of signs and symptoms of underlying disease. This may complicate the problem, create drug resistance and delay the diagnosis and cause adverse drug reaction. ${ }^{(3,4,5)}$ This raises the concerns of incorrect self-diagnosis, drug interaction, and use of drugs other than for the original indication. (6) 
The advancement in the field of communication and availability of information on fingertip has lead to easy access to the knowledge of medicine even to general population. Other factors like internet, ready access to drugs, and influence of advertisements and previous experience of treating similar illness have influenced the practice of self medication. $(2,7)$

Medical students being exposed to the subjects in medicine are more prone for self medication which may, at times leads to untoward consequences. Medical students are more likely of taking self medication since they have easy access to information from drug indices, literature, and other medical students to self-diagnose and self-medicate. (8) In addition, they have easy access to the medication itself through physician samples provided by pharmaceutical representatives, and "The White Coat" guarantees trouble free access to drugs available in phar macies.(8)

Though several studies have been carried out in different populations to evaluate the practice of self-medication there is a paucity of studies on self-medication among medical students. (9) The present study was undertaken to identify the reasons for, and the patterns of, self-medication among medical students

OBJECTIVE: To study the pattern of self medication among medical students and to determine the factors affecting it.

\section{METHODS:}

Study type: Cross-sectional descriptive study

Study tool: A structured questionnaire was designed by reviewing relevant literatures and questionnaires previously used in similar studies. The study questionnaire was first pre-tested and suitable modifications were done. The final version of the question naire was distributed.

Methodology: This cross sectional descriptive study was conducted at Kannur Medical College, Kannur, North Kerala from March $15^{\text {th }}$ to April 20th 2013. KMC has a total of 400 medical students out of which 302 students who were willing to participate and available during study period were enrolled in the study. It was a purposive sampling and students were selected randomly. The study sample had a representation from all phases/batches (first, second, third and final phase) of medical course, accounting to 77, 84, 63 and 78 students from first, second, third and final phase of MBBS course. A briefing was given about the nature of the study and informed consent was obtained. For the purpose of the study, certain operational terms were explained to the students and appropriate instructions about filling the questionnaire were given and confidentiality was ensured. The study subjects were informed that the information collected would be anonymous; and participation would be totally voluntary. History of self-medication in last 6 months was taken. The data was collected by using self administered questionnaire which included the various aspects of self medication.

Ethical clearance: The study was approved by Institutional Ethical Committee of Kannur Medical College, Anjarakandy

Statistical analysis: After collection of data, information gathered was entered into Microsoft excel 2007 version \& analyzed by using Percentage/proportions and presented in suitable tabular and graphical forms. 
RESULTS: Table 1 shows that, 302 medical students participated in the study, of which 78 (25.8\%) were males \& 224 (74.2\%) were females. Participants included from all the batches of medical course making to $37.9 \%, 27.8 \%, 20.8 \%$ \& $25.8 \%$ of representation from first, second, third \& final phase of course.

It was found that out of 302 students, 196 (64.9\%) students practiced self medication. Practice of self medication was $16.9 \%$ at first phase and rose to $57.1 \%$ by second phase followed by a steep rise reaching $90.5 \%$ by third phase to $100 \%$ of students practiced self medication at final phase. (Table 2)

The practice of self medication was high both in male (66.66\%) and female (64.3\%) medical students, but it was slightly higher in males compared to females. (Table 3)

The study revealed that, the most common source/ reference used for self medication are the seniors (89.8\%), followed by previous prescriptions (87.2\%). Textbooks and friends also contributed to a significant proportion (59.7\%). (Figure 1)

The most common reason quoted for taking self medication was fever $(70.4 \%)$ followed by common cold (67.8\%) and headache/bodyache (64.7\%). (Figure 2). Figure 3 shows that females (77.8\%) used to take self medication more frequently than males (65.4\%)

The study reflects that analgesics (79.6\%) and antipyretics (79.6\%) were the most common drugs used for self medication followed by anti-histaminic (72.4\%) and antacids (65.3\%). 30.1\% of them took antibiotics and $9.7 \%$ sedatives without prescription. (Figure 4)

Among those who took antibiotics (30.1\%), only $11.9 \%$ (7) of them completed the course of antibiotic. $80.1 \%$ (157) of those who took self medication said that they prescribed drugs for others also (friends/relatives). None of them reported of experiencing any side effect. Most of them purchased drugs from private pharmacy shop near the college. (Not shown in table).

DISCUSSION: This cross-sectional study conducted involving 302 medical students comprising from all the phases of medical course revealed that the overall prevalence of self medication was $64.9 \%$.

The studies on self-medication have reported various prevalence figures, ranging from $26.2 \%{ }^{(10)}$ to as high as $92 \%(8,11)$

This overall prevalence observed in our study may be because of the influence of prevalent lesser practice among first phase students. First phase students being not much different from general public in their knowledge about medicine, showed a lower prevalence of $16.9 \%$. The overall prevalence in pre-final and final phase students accounts to $95.7 \%$.

The study also showed that the practice of self medication rose drastically from being $16.9 \%$ at first phase to $57.7 \%$ at second, $90.5 \%$ at third phase to $100 \%$ at final phase of medical course indicating that students tend to self medicate by gaining experience from their exposure to the medical subjects.

It was observed in the study that the prevalence of self medication was more in males compared to female students as similar to study done by Badiger $S$ et al (8), but females used to self medicate more frequently than males.

Seniors, previous prescriptions and books were the commonly quoted sources of reference for drug information in similar to the observations made by Badiger S(8) and Sontakke SD. (12) There were several indications for self-medication the most common indications in our study were fever, cold \& head/bodyache and most commonly used class of drugs were analgesics, antipyretics and 
antihistamines which was in concordance with observations made by Badiger $\mathrm{S}^{(8)}$, James $\mathrm{H}^{(9)}$ and Parikh D.(13)

$30.1 \%$ of students reported to self medicate antibiotics of which only $11.9 \%$ completed the full course of treatment.(8) $9.7 \%$ took sedatives/anxiolytics without proper prescription. $80.1 \%$ (157) of those students who practiced self-medication, suggested medication to relatives and friends which may put them to risk of inappropriate drugs. The most common source for purchasing drugs was private pharmacies near the college in similarity to observations of James H.(9) This may be because of their influence and image of being medical students and easy procurement from pharmacist.

CONCLUSION: This practice of self medication, without proper consultation from qualified practitioner is widely prevalent in medical students especially among third and final phase students. This may possibly mask the initial signs and symptoms of diseases and lead to making a wrong diagnosis and risk of using a wrong drug. Self medication increases the chances of illicit use of $\operatorname{drug}(14)$

The motivating factors for self medication could be; easy availability of prescription drugs across the counter without a valid prescription, lack of stringent controls over medical advertising.(13)

This highlights the importance of impressing the students about the dangers of self medication, their misuse and their responsibility.

ACKNOWLEDGEMENT: We would like to express our gratitude to all the respondents for spending their valuable time to answer our questionnaire that helped us to successfully complete our study. Authors are also thankful to the institutional ethical committee of Kannur Medical College that permitted to conduct the study.

\section{REFERENCE:}

1. World Health Organization (WHO). Guidelines for the regulatory assessment of Medicinal Products for use in self-medication. http://apps.who.int/medicinedocs/en/d/Js2218e/

2. Ezz NFAE, Elarab HSE. Knowledge, attitude and practice of medical students towards self medication at Ain Shams University, Egypt. J prev med hyg. 2011; 52: 196-200.

3. Ferris DG, Nyirjesy P, Sobel JD, Soper D, Pavletic A, Litaker MS. Over the Counter Antifungal Drug Misuse Associated With Patient Diagnosed Vulvovaginal Candidiasis. Obstet Gynecol. 2002 Mar; 99(3):419-25.

4. Bauchner H, Wise P. Antibiotics without prescription: "bacterial or medical resistance"? Lancet 2000; 355: 1480-84.

5. Calabresi P, Cupini LM. Medication-overuse headache: similarities with drug addiction. Trends Pharmacol Sci 2005; 26: 62-8.

6. Zafar SN, Syed R, Waqar S, Zubairi AJ, Vaqar T et al.Self-medication amongst University Students of Karachi: Prevalence, Knowledge and Attitudes. J Pak Med Assoc.2008;58(4):214217. 
7. Patel MM, Singh U, Sapre C, Salvi K, Shah A, Vasoya B. Self-medication practices among college Students: A cross sectional study in Gujarat. National Journal of Medical Research.2013;3(3):257-260.

8. Badiger S, Kundapur R, Jain A, Kumar A, Patanashetty S, Thakolkaran N, Bhat, Ullal N. Self medication patterns among medical students in South India. AMJ 2012, 5, 4, 217-220. http//dx.doi.org/10.4066/AMJ.2012.1007.

9. James H, Handu SS, Khaja KAJ, Otoom S, Sequeira RP. Evaluation of the Knowledge, Attitude and Practice of Self-Medication among First-Year Medical Students. Med Princ Pract 2006; 15:270-275.

10. Martins AP, Miranda AC, Mendes Z, Soares MA, Ferreira P, Nogueira A: Self-medication in a Portuguese urban population: a prevalence study. Pharmacoepidemiol Drug Saf 2002; 11: 409-414.

11. Abahussain E, Matowe LK, Nicholls PJ: Self reported medication use among adolescents in Kuwait. Med Princ Pract 2005; 14: 161-164.

12. Sontakke SD, Bajait CS, Pimpalkhute SA, Jaiswal KM, Jaiswal SR. Comparative study of evaluation of self-medication practices in first and third year medical students. Int J Biol Med Res. 2011; 2(2): 561-564.

13. Parikh D, Sattigeri BM, Kumar A, Brahmbhatt S. A survey study on use of over the counter (OTC) drugs among medical students, nursing and clerical staff of a tertiary care teaching rural hospital. Int J Res Med Sci 2013;1:83-6.

14. Sean Esteban McCabe, Christian J. Teterb and Carol J. Boyda. Illicit use of prescription pain medication among college students. Drug and Alcohol Dependence 2005; 77(1): 37-47.

\begin{tabular}{|c|c|c|c|}
\hline Phase of medical course & $\begin{array}{c}\text { Males } \\
\text { Number (\%) }\end{array}$ & $\begin{array}{c}\text { Females } \\
\text { Number (\%) }\end{array}$ & $\begin{array}{c}\text { Total } \\
\text { Number (\%) }\end{array}$ \\
\hline First phase & $25(32.5)$ & $52(67.5)$ & $\mathbf{7 7 ( 1 0 0 )}$ \\
\hline Second phase & $16(19)$ & $68(81)$ & $\mathbf{8 4 ( 1 0 0 )}$ \\
\hline Third phase & $22(34.9)$ & $41(65.1)$ & $\mathbf{6 3 ( 1 0 0 )}$ \\
\hline Final phase & $15(19.2)$ & $63(80.8)$ & $\mathbf{7 8 ( 1 0 0 )}$ \\
\hline Total & $\mathbf{7 8 ( 2 5 . 8 )}$ & $\mathbf{2 2 4 ( 7 4 . 2 )}$ & $\mathbf{3 0 2 ( 1 0 0 )}$ \\
\hline
\end{tabular}

Table 1: Distribution of medical students by gender and Phase of medical course

\begin{tabular}{|c|c|c|c|}
\hline \multirow{2}{*}{ Phase of medical course } & \multicolumn{3}{|c|}{ Practice of self medication } \\
\cline { 2 - 4 } & $\begin{array}{c}\text { Yes } \\
\text { Number (\%) }\end{array}$ & $\begin{array}{c}\text { No } \\
\text { Number (\%) }\end{array}$ & $\begin{array}{c}\text { Total } \\
\text { Number (\%) }\end{array}$ \\
\hline First Phase & $13(16.9)$ & $65(84.4)$ & $\mathbf{7 7 ( 1 0 0 )}$ \\
\hline Second Phase & $48(57.1)$ & $36(42.9)$ & $\mathbf{8 4}(\mathbf{1 0 0 )}$ \\
\hline Third Phase & $57(90.5)$ & $6(9.5)$ & $\mathbf{6 3 ( 1 0 0 )}$ \\
\hline Final Phase & $78(100)$ & $0(0)$ & $\mathbf{7 8 ( 1 0 0 )}$ \\
\hline Total & $\mathbf{1 9 6 ( 6 4 . 9 )}$ & $\mathbf{1 0 7 ( 3 5 . 1 )}$ & $\mathbf{3 0 2 ( 1 0 0 )}$ \\
\hline
\end{tabular}

Table 2: Distribution of medical students by the practice of self medication 


\section{ORIGINAL ARTICLE}

\begin{tabular}{|c|c|c|c|}
\hline \multirow{2}{*}{ Gender } & \multicolumn{3}{|c|}{ Practice of self medication } \\
\cline { 2 - 4 } & $\begin{array}{c}\text { Yes } \\
\text { Number (\%) }\end{array}$ & $\begin{array}{c}\text { No } \\
\text { Number (\%) }\end{array}$ & $\begin{array}{c}\text { Total } \\
\text { Number (\%) }\end{array}$ \\
\hline Male & $52(66.66)$ & $26(33.34)$ & $\mathbf{7 8 ( 1 0 0 )}$ \\
\hline Female & $144(64.3)$ & $80(35.7)$ & $\mathbf{2 2 4 ( 1 0 0 )}$ \\
\hline Total & $\mathbf{1 9 6 ( 6 4 . 9 )}$ & $\mathbf{1 0 6 ( 3 5 . 4 )}$ & $\mathbf{3 0 2 ( 1 0 0 )}$ \\
\hline
\end{tabular}

Table 3: Practice of self medication and gender

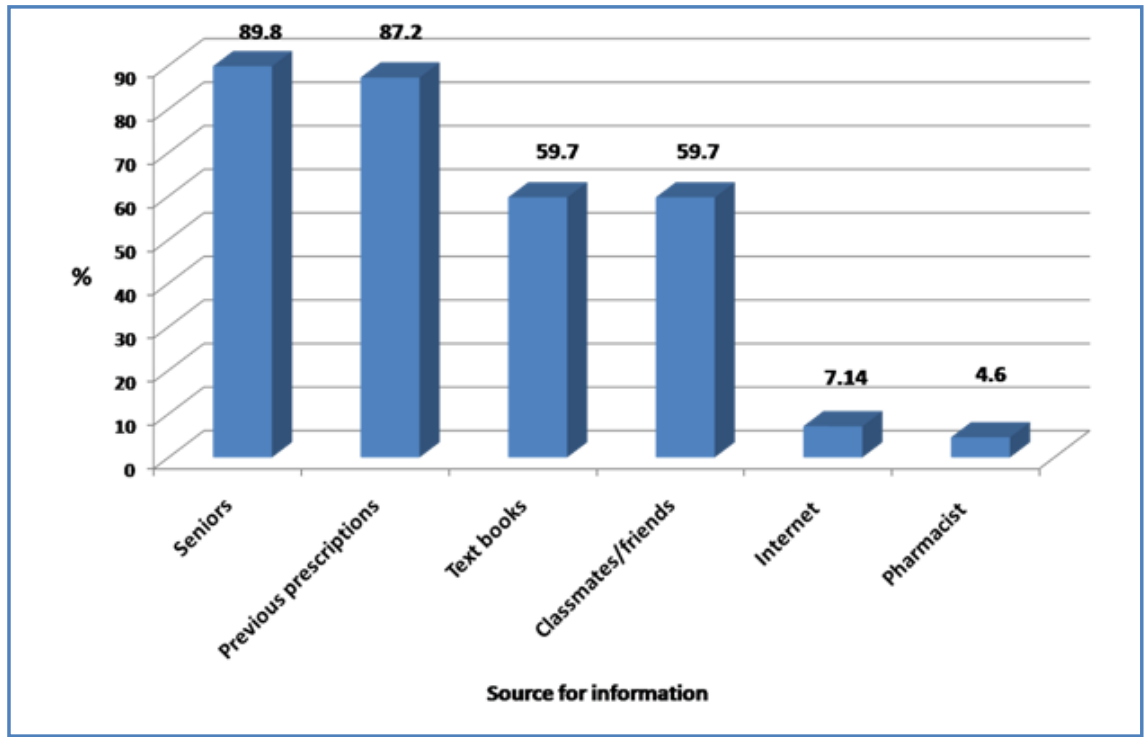

Figure 1: Distribution of medical students by source of reference for self medication

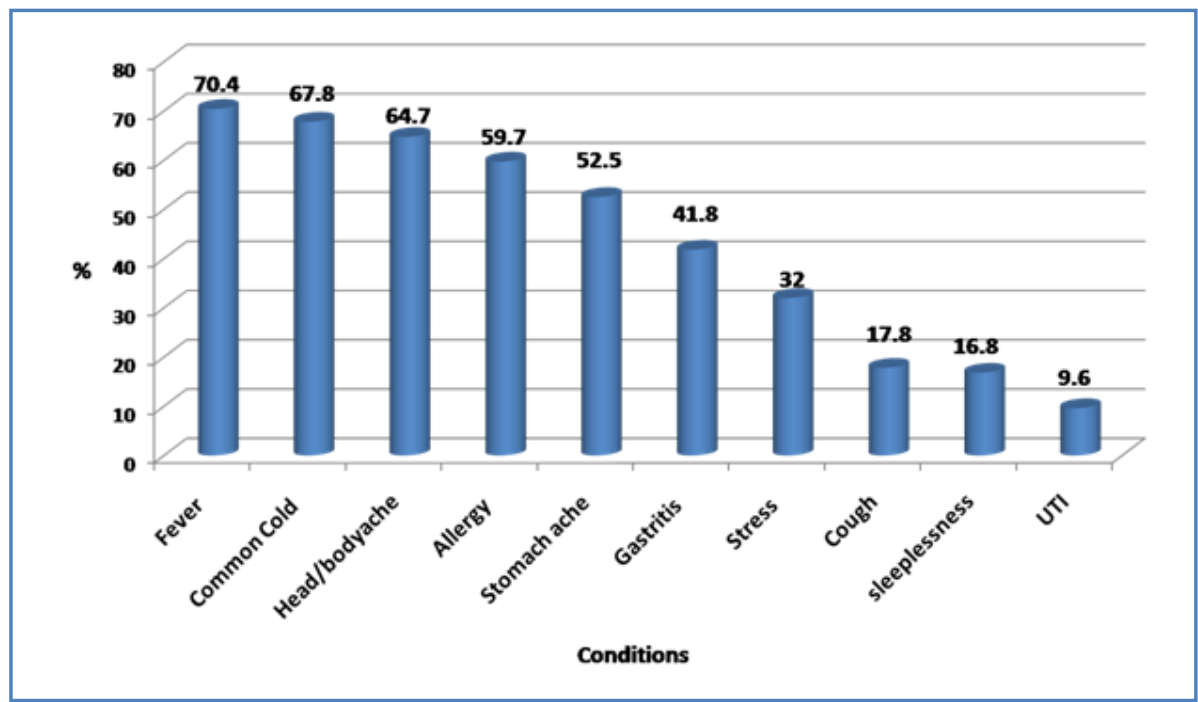

Figure 2: Conditions for taking self medication 


\section{ORIGINAL ARTICLE}

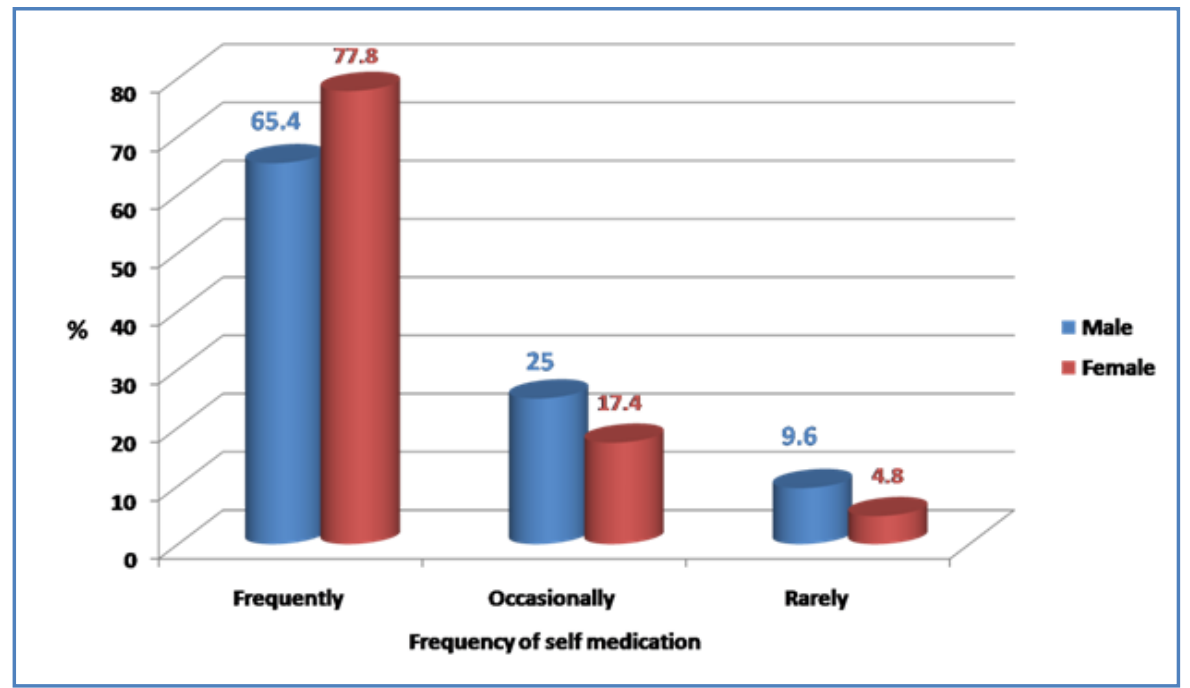

\section{Figure 3: Distribution of students by gender and frequency of self medication}

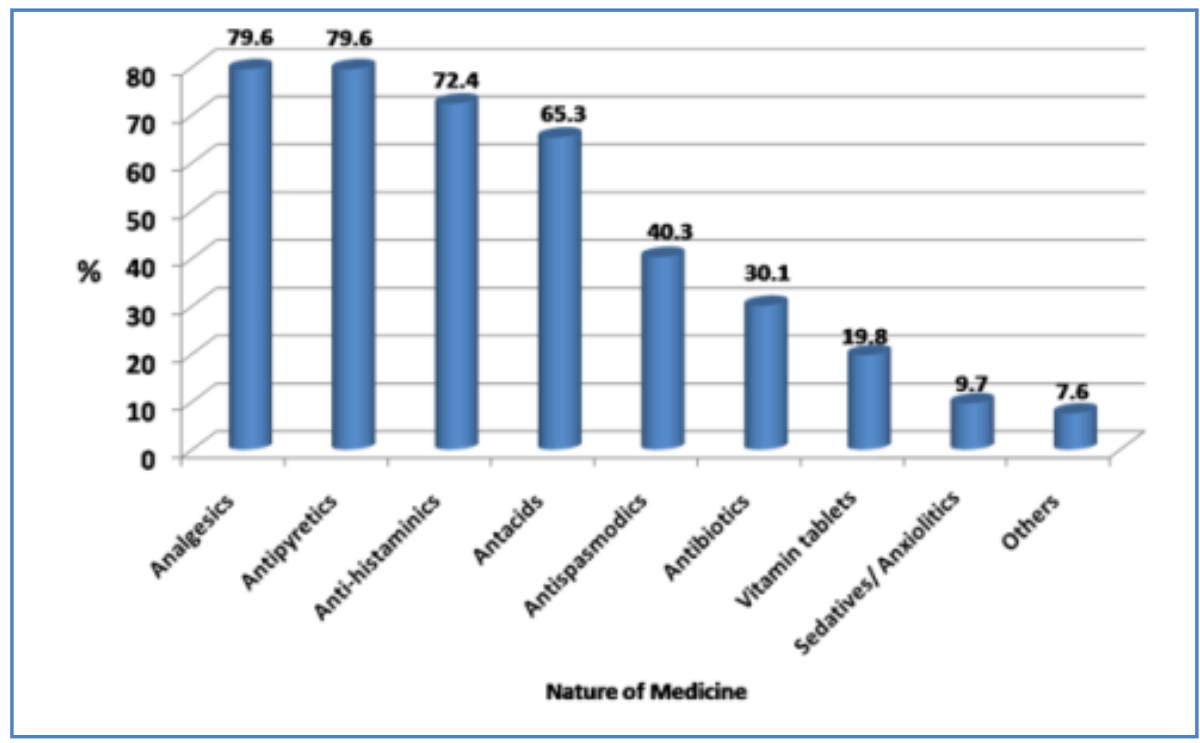

Figure 4: Showing the drugs that are used for self medication 


\section{AUTHORS:}

1. Girish H.O.

2. Divya H.M

3. Sarada Prabhakaran

4. Venugopalan P.P.

5. Raghavend raswamy Ko ppad

6. Abhishek Acharya

\section{PARTI CULARS OF CONTRIBUTORS:}

1. Assistant Professor, Department of Community Medicine, Subbaiah Institute of Medical Sciences \& Research Centre, Shimoga.

2. Assistant Professor, Department of Community Medicine, Subbaiah Institute of Medical Sciences \& Research Centre, Shimoga.

3. Associate Professor, Department of Community Medicine, Kannur Medical College, Kannur, Keral a.

4. Professor, Department of Community Medicine, Kannur Medical College, Kannur, Kerala.
5. Assistant Professor, Department of Community Medicine, Shimoga Institute of Medical Science, Shimoga.

6. Assistant Professor, Department of Community Medicine, Subbaiah Institute of Medical Sciences \& Research Centre, Shimoga

\section{NAME ADDRESS EMAIL ID OF THE CORRESPONDING AUTHOR:}

Dr. Girish H.O., Assistant Professor,

Department of Community Medicine,

Subbaiah Ins titute of Medical Sciences \& Research Centre, Shimoga, Karnataka, India.

Email - dr.gi rishmysore@gmail.com

Date of Submission: 24/10/2013.

Date of Peer Review: 25/10/2013.

Date of Acceptance: 29/10/2013.

Date of Publishing: 05/11/2013 